\title{
Variations in Tribological Characteristics of SM45C by PVD Coating and Thin Films
}

\author{
Hyun-Bo Shim*, Chang-Min Suh ${ }^{* * * * * *}$, Jong-Hyoung Kim ${ }^{* * * * *}$ and Min-Soo Suh ${ }^{* * * * *}$ \\ "School of Mechanical Engineering, Yeungnam University, Kyungsan, Korea \\ ${ }^{* *}$ School of Mechanical Engineering, Kyungpook Nat'l University, Daegu, Korea \\ ${ }^{* * *}$ DMI Senior Fellow, Daegu, Korea \\ ${ }^{* * * *}$ Korea Institute of Industrial Technology, Daegu, Korea \\ ${ }^{* * * * * *}$ Korea Institute of Energy Research, Daejun, Korea
}

\section{SM45C재의 PVD코팅과 필름에 의한 트라이볼러지 특성}

\author{
심현보 \\ "영남대학교 기계공학부 \\ *경북대학교 기계공학부 \\ **k대구기계부품연구원 자문위원 \\ ****간국생산기술연구원 \\ ***k* 한국에너지연구원
}

KEY WORDS: Tibology 트라이볼러지, Press die 프레스 금형, SM45C, Surface hardness 표면경도, CrN 크롬질화코팅, Concept multi-coating 개념 다층코팅, Physical vapor deposition PVD 물리증착, Thin film 얇은 필름

\begin{abstract}
In order to accumulate data to lower the friction coefficient of a press mold, tribological tests were performed before and after coating SM45C with a PVC/PO film and plasma coating ( $\mathrm{CrN}$, concept). The ultrasonic nanocrystal surface modification (UNSM)-treated material had a nano-size surface texture, high surface hardness, and large and deep compressive residual stress formation. Even when the load was doubled, the small amount of abrasion, small weight of the abrasion, and width and depth of the abrasion did not increase as much as those of untreated materials. A comparison of the weight change before and after the tribological test with the $\mathrm{CrN}$ and the concept coating material and that of the untreated material showed that the wear loss of the concept coating material and P-UNSM treated material (that is, the UNSM treated material treated with the concept coating) showed a tendency to decrease by approximately 55-75\%. Concept $100 \mathrm{~N}$ had a lower friction coefficient of about 0.6 , and P-UNSM-30-100N showed almost the same curve as concept $100 \mathrm{~N}$ and had a low coefficient of friction of about 0.6. The concept multilayer coating had a thickness of $5.32 \mu \mathrm{m}$. In the beginning, the coefficient of friction decreased because of the plasma coating, but it started to increase from about 250-300 s. After about 350 s, the coefficient of friction tended to approach the friction coefficient of the SM45C base metal. The SGV-280F film-attached test specimen was slightly pushed back and forth, but the SM45C base material was not exposed due to abrasion. The friction coefficient was 0.22, which was the lowest, and the tribological property was the best in this study.
\end{abstract}

\section{1. 서 론}

본 연구는 앞선 연구인 " $\mathrm{SM} 45 \mathrm{C}$ 재의 $\mathrm{UNSM}$ 처리에 의한 트 라이볼러지 특성 변화”의 연속 연구이며, 본 연구의 배경은 다 음과 같다. 즉 액화된 천연가스를 수송하는 화물선은 가스의 운 송에 액압과 파도에 따른 요동과 부하변동에 따라 $-162^{\circ} \mathrm{C}$ 하에 서 동적변동 하중 하에서 운전된다. 따라서 이런 변동하중과 요
동현상의 복합작용에 의한 운송용기의 파손을 방지하고, 용기 의 경량화와 극저온하의 내구성을 얻기 위해서 소재에 대한 마 찰, 마모현상을 최소화 할 수 있는 현장용의 정량적인 자료의 축적이 요구되고 있다.

여기에는 이러한 LNG 선박용 운송용기에 사용되고 있는 소재는 극저온 하에서 기계적인 성질, 피로강도, 용접성, 내식성 등이 사용 용도에도 만족되어야만 사용가능하다. 이 LNG 선박용 운송용기의

Received 29 August 2018, revised 20 November 2018, accepted 13 December 2018

Corresponding author Chang-Min Suh: cmsuh@knu.ac.kr ORCID: http://orcid.org/0000-0001-7034-8764

(C) 2018, The Korean Society of Ocean Engineers

This is an open access article distributed under the terms of the creative commons attribution non-commercial license (http://creativecommons.org/licenses/by-nc/3.0) which permits unrestricted non-commercial use, distribution, and reproduction in any medium, provided the original work is properly cited. 
소재는 현재 STS 304L(오스테나이트계 스테인레스강) 등이 널리 사용되고 있다(Chun et al., 2009; Kim et al., 2010; Kim et al., 2011, Kim et al., 2013; Yu et al., 2013; Suh et al., 2016).

따라서 본 과제에는 금형재질인 $\mathrm{SM} 45 \mathrm{C}$ 를 사용하여 표면증착 방식으로 플라즈마 코팅(Plasma coating)인 PVD(Physical vapor deposition) 방식 중에 포밍 금형에 적합한 Concept 다층 코팅 $\left(\mathrm{CrWN} / \mathrm{TiCN} / \mathrm{TiCN}_{2}\right)$ 과 CrN코팅 및 $\mathrm{PVC}($ Polyvinyl chloride) / $\mathrm{PO}$ (Polyolefin)필름에 따른 마찰계수의 특성변화를 시험 평가한다.

또한 새로운 표면처리기술로 마이크로 포징(Micro forging)기 술인 초음파나노표면개질(UNSM, Ultrasonic nanocrystal surface modification) 기술을 PVD기술과 연관시켜 멤브레인 두께감소와 면굴곡을 최소화할 수 있는 윤활방법, 즉 표면처리방법과 필름 재료를 선택할 수 있도록 자료를 축적하고자 한다(Amanov et al., 2012; Amanov et al., 2014; Gim and Jeong, 2007; Jeon et al., 2014; Lee et al., 2015; Pyun et al., 2012; Suh et al., 2016).

\section{2. 시험방법과 실험장비}

\section{1 초음파 나노표면 처리법에 따른 시험편의 분류}

Fig. 1(a)는 UNSM(Ultrasonic nanocrystal surface modification) 조건을 $30 \mathrm{~N}, 40 \mathrm{~N}, 50 \mathrm{~N}$ 의 3 가지 조건으로 처리하여 UNSM-30N,

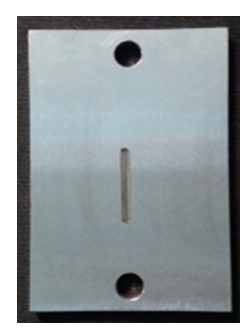

(a)

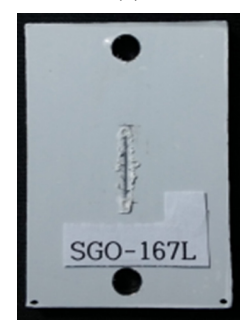

(c)

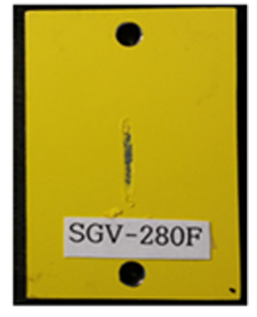

(b)

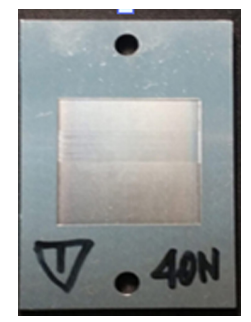

(d)
Fig. 1 Appearance of the test specimens: untreated specimen (a), thin film coated SGV-280F (b) and SGV-167L (c), concept coated specimens after UNSM-40N treated (d)

Table 1 Chemical composition of SM45C [wt \%]

\begin{tabular}{ccccc}
\hline \hline $\mathrm{C}$ & $\mathrm{Mn}$ & $\mathrm{P}$ & $\mathrm{S}$ & $\mathrm{Fe}$ \\
\hline $0.42 \sim 0.5$ & $0.6 \sim 0.9$ & $<0.04$ & $<0.04$ & $98.51 \sim 98.98$ \\
\hline
\end{tabular}

Table 2 Tribology test conditions of SM45C

\begin{tabular}{cccccc}
\hline \hline $\begin{array}{c}\text { Load } \\
{[\mathrm{N}]}\end{array}$ & $\begin{array}{c}\text { Speed } \\
{[\mathrm{Hz}]}\end{array}$ & $\begin{array}{c}\text { Stroke } \\
{[\mathrm{mm}]}\end{array}$ & $\begin{array}{c}\text { Time } \\
{[\mathrm{min}]}\end{array}$ & $\begin{array}{c}\text { Counter part } \\
(\text { SAE2100, } \\
\text { SM45C) }\end{array}$ & Condition \\
\hline 50,100 & 2 & 15 & 30 & $d=10 \mathrm{~mm}$ & Dry \\
\hline
\end{tabular}

UNSM-40N, UNSM-50N으로 칭하였다. 또 이 처리재에 Concept 다층 코팅을 실시하여 마찰계수의 특성변화를 시험평가하면서 P-UNSM와 같이 표기하였다(Amanov et al., 2012; Amanov et al., 2014; Lee et al., 2015; Suh et al., 2007).

\section{$2.2 \mathrm{SM} 45 \mathrm{C}$ 의 시험편과 트라이볼러지 시험 방법}

본 시험에서 사용한 마모시험편은 Fig. 1(a)와 같이 $38 \times 58 \times 4$ $(\mathrm{mm})$ 크기의 직사각형인 $\mathrm{SM} 45 \mathrm{C}$ 재 시험편을 사용하였고, 시험 편의 화학적 성분은 Table 1 과 같다. 또 동재료의 인장강도는 $625 \mathrm{MPa}$, 항복강도 $530 \mathrm{MPa}$, 비커스 경도 210 이다.

트라이볼러지 시험의 조건은 Table 2 와 같다. 시험편의 표면은 $\mathrm{SM} 45 \mathrm{C}$ 재를 기계가공 후 연마하여 사용하였다. Fig. 1(b)와 Fig. $1(\mathrm{c})$ 는 $\mathrm{PVC} / \mathrm{PO}$ 필름을 부착한 시험편이며, Fig. $1(\mathrm{~d})$ 는 UNSM처리 후 Concept 다층코팅된 것을 예시한 것이다. Fig. 1의 트라이볼러 지 시험편은 $50 \mathrm{~N}$ 과 $100 \mathrm{~N}$ 의 부하하중에서 1,800 초간 시험을 실시 하였다.

\section{3 시험장비}

본 연구에 사용된 트라이볼러지 시험장비는 Fig. 2와 같이 왕복 식 시험기인 TE77 AUTO(Plint \& partners, England)를 사용하였다. 표면 거칠기를 측정하기 위해 거칠기 측정기(Form Talysurf PGI, Taylor Hobson, England)을 사용하였으며, 형상을 측정하기 위해 형상측정기(XC10, Mahr, Germany)를 사용하였다. 또 경도 측정용 으로 비커스경도기(Mitutoyo MVK-E3, Japan)와 로크웰경도 측정 장비(Wolpert testor 2000, Instron Corp. USA)를 사용하였다. Micro dimples를 확인하기 위해 AFM(Atomic force microscope, SPA400, Japan)을 사용하였다. 그리고 $\operatorname{SEM(Scanning~electron~microscope)ㅅㅏ~}$ 진은 FE-SEM(S-4300, Hitachi, Japan)장비를 사용했으며, 표면스크 래치 장비는 Accretech(Surfcom $1500 \mathrm{sd} 3$, Japan)를 사용하였다.

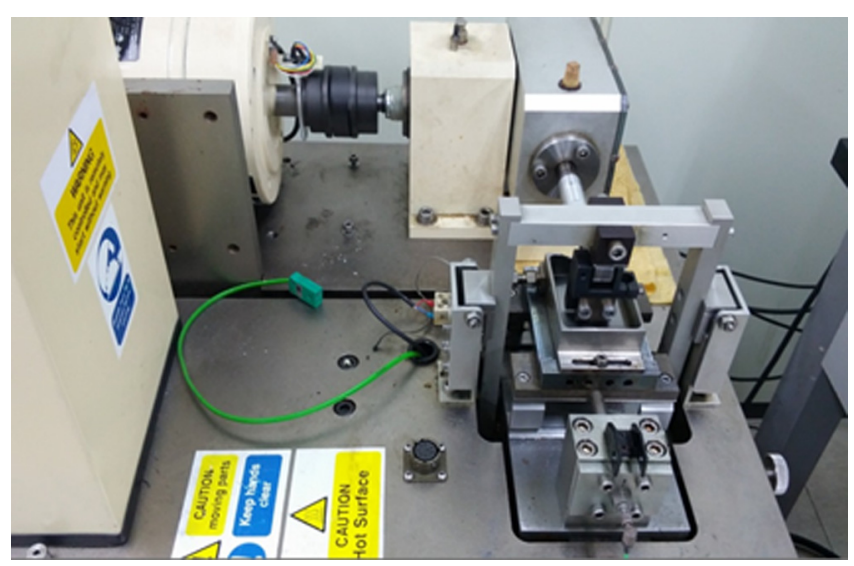

Fig. 2 Tribology experimental apparatus

\section{4. 코팅층의 밀착상태 평가 및 두께측정 방법}

Table 3에는 본 연구에 채택된 플라즈마 코팅의 종류와 특징을 정리하였다. 이러한 세라믹 코팅은 Fig. 3의 Mercedes adhesion test를 통하여 코팅된 박막의 표면 밀착상태를 확인, 평가하는 시 험법을 사용하였다. 이 시험법은 경도측정기를 사용하여 Fig. $3(\mathrm{a})$ 와 같은 원리로 $500 \mathrm{~N}$ 과 $1,000 \mathrm{~N}$ 하에서 실시하여 코팅층의 밀 착상태를 확인한다. 이 때 코팅층은 Fig. 3(b)와같이 HF1(완전 밀 
Table 3 Conditions of plasma coating

\begin{tabular}{|c|c|c|}
\hline Coating & $\mathrm{CrN}$ & Concept \\
\hline Type & \multicolumn{2}{|c|}{ Arc ion plating } \\
\hline Hardness & $H v_{0.05} 2,200$ & $H v_{0.05} \quad 3,000$ \\
\hline Layer & Mono & Multi \\
\hline Temperature & \multicolumn{2}{|c|}{$420 \sim 480{ }^{\circ} \mathrm{C}$} \\
\hline Voltage & $-40 \mathrm{~V}$ & $-100 \mathrm{~V}$ \\
\hline
\end{tabular}

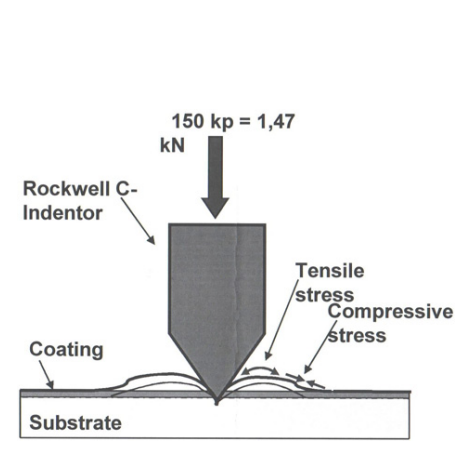

(a)

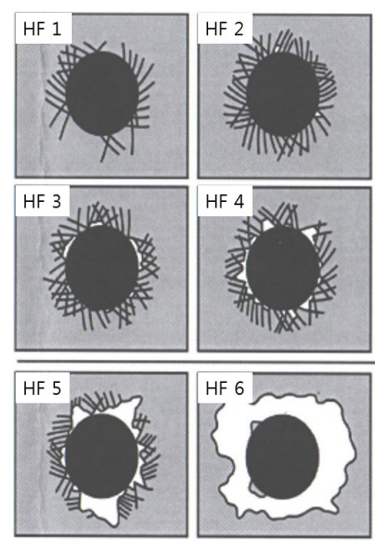

(b)
Fig. 3 Mercedes adhesion test

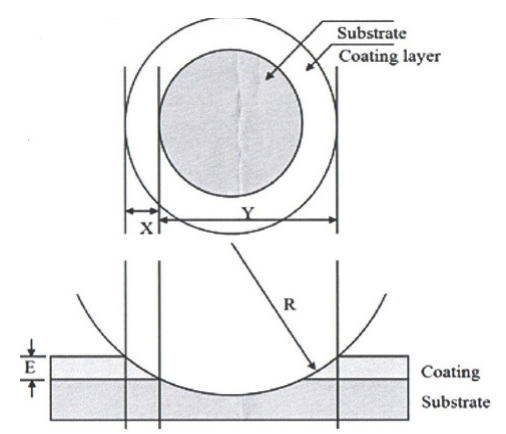

$$
E=\frac{X Y}{2 R}
$$

E : thickness of Coating layer $\mathbf{R}$ : Radius of steel ball

Fig. 4 Method of thickness measurement

Table 4 The thickness and the degree of adhesion of the coating layer

\begin{tabular}{ccc}
\hline \hline Coating & Adhesion state & Thickness $[\mu \mathrm{m}]$ \\
\hline Concept & HF1 2 & 5.32 \\
CrN & HF1 2 & 3.41 \\
\hline
\end{tabular}

착) HF6(완전 박리)까지 분류된다. 본 연구에 사용된 마모시험 편의 코팅층은 Table 4 와 Fig. 5 와 같이 $\mathrm{HF} 1 \sim \mathrm{HF} 2$ 으로 코팅층이 박리(Delamination)현상이 없는 양호한 밀착상태로 코팅되었음을 확인하였다.

또 코팅층의 두께는 Fig. 4와 같이 베어링 볼의 마모에 의하 여 측정한 결과 Table 4와 같이 Concept 다층코팅은 $5.32 \mu \mathrm{m}$, $\mathrm{CrN}$ 는 $3.41 \mu \mathrm{m}$ 로 각각 측정되었다. Fig. 5는 본 연구에 사용된 코팅층의 밀착상태의 등급판정과 코팅층의 두께를 측정한 결과 를 예로서 나타내었다.

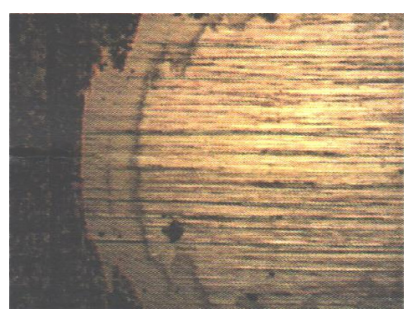

(a) Concept

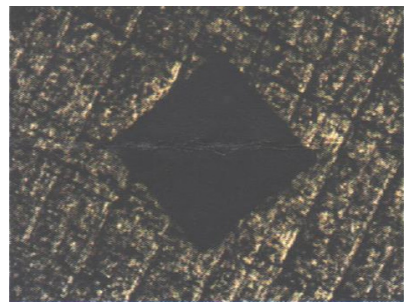

(c) Concept

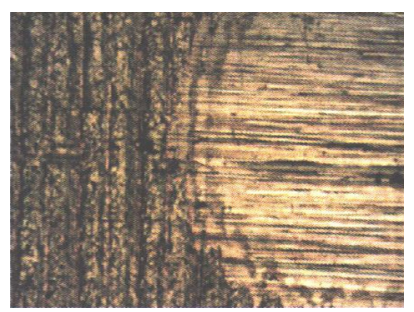

(b) $\mathrm{CrN}$

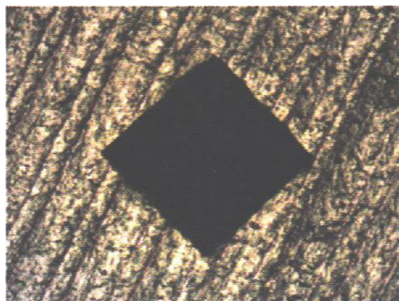

(d) $\mathrm{CrN}$
Fig. 5 The thickness and the degree of adhesion of the coating layer

\section{3. 시험 결과 및 고찰}

\subsection{PO/PVC계 필름의 트라이볼러지 시험}

Fig. 6과 Table 5는 3가지 필름을 SM45C 시험편에 부착하여 Dry 조건으로 $50 \mathrm{~N}$ 하에서 트라이볼러지 시험한 결과를 정리한 것이다.

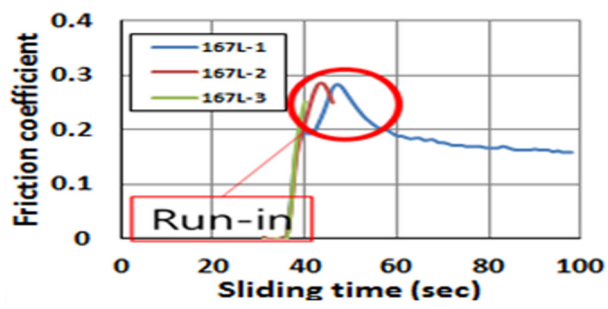

(a) PO film- $50 \mathrm{~N}$

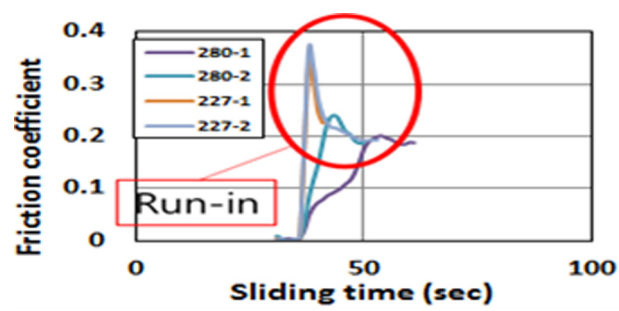

(b) PVC film-50N

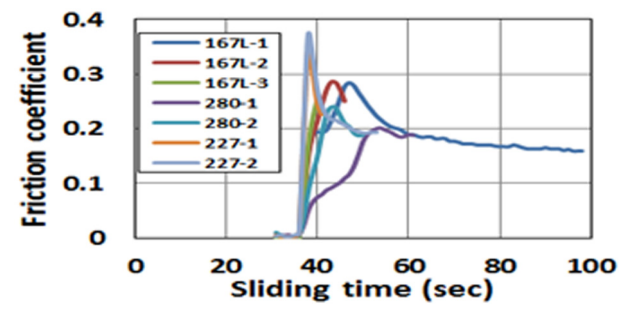

(c) PO / PVC films-50N

Fig. 6 Comparison of friction coefficient as a function at a normal load of $50 \mathrm{~N}$ on the PO / PVC films 
Table 5 Comparison of friction coefficient of the PO/PVC film conditions.

\begin{tabular}{ccccc}
\hline \hline Film & $\begin{array}{c}\text { Actual test } \\
\text { time } \\
{[\mathrm{sec}]}\end{array}$ & $\begin{array}{c}\text { Friction } \\
\text { coefficient }\end{array}$ & Color & $\begin{array}{c}\text { Film } \\
\text { thickness } \\
{[\mathrm{mm}]}\end{array}$ \\
\hline $\begin{array}{c}\text { SGO-167L } \\
\text { (PO) }\end{array}$ & 16 & 0.284 & & \\
& 09 & 0.285 & White & 0.1 \\
SGV-280F & 23 & 0.252 & & \\
(PVC) & 12 & 0.201 & Yellow & 0.11 \\
SGV-227 & 07 & 0.342 & & \\
(PVC) & 07 & 0.371 & White & 0.1 \\
\hline
\end{tabular}

Fig. 6(a)는 백색 PO 필름인 SGO-167L 재의 결과로 실험시간 인 횡축을 확대하여 정리하였고, $\mathrm{SM} 45 \mathrm{C}$ 에 시험한 경우와 같이 31 초 후에 작동되어 기록이 시작되었다. 그 후 1 번 시편은 47 초 에 마찰계수 0.284 로 되었고, 98초 후에 0.159로 감소하였다. 2 번 시편은 44 초에 마찰계수 0.285 로 되었고, 46 초 후에 실험을 중단하였으며, 3 번 시편은 40 초에 마찰계수 0.252 로 되었다.

Fig. 6(b)는 노란색 PVC 필름인 SGV-280F과 백색 PVC 필름 인 SGV-227으로 트라이볼러지 시험한 결과이며, Fig. 6(a)와 같 이 31 초 후에 작동되어 기록이 시작되었다. 그 후 $\mathrm{SGV}-280 \mathrm{~F}$ 재 의 1 번 시편은 54 초에 마찰계수 0.201 로 되었고, 2 번 시편은 43 초 후에 0.239 로 감소하였다. SGV-227재의 1 번 시편은 38 초에 마찰계수 0.342 로 되었고, 2 번 시편은 38 초 후에 0.371 로 감소하 였다.

Fig. 6(c)는 Fig. 6(a)와 Fig. 6(b)의 자료를 동시에 비교하여 나 타낸 것이다. Table 5는 Fig. 6의 트라이볼러지 시험 결과와 자 료를 종합한 것으로 마찰계수가 실제작동 시간의 약 20 초 이내 에 초기진입모드를 형성하였다. 여기서 Run-in은 상대재와 모재 인 $\mathrm{SM} 45 \mathrm{C}$ 위의 필름의 마찰과 연계되며, 필름 재료의 티어링과 도 연계되는 최고값이 계측되었다.

Table 5에는 필름이 모재 표면을 보호하며 찢어지기 전까지의 마찰계수와 마찰 시험시간을 분석하였다. 이러한 7가지 필름 부 착시편의 트라이볼러지 시험결과 노란색 $\mathrm{PVC}$ 필름이 3 가지 필 름 중에 가장 트라이볼러지 시험시간이 길고, 마찰계수가 평균 0.22 로 가장 낮았다. 그 원인은 다른 필름과 달리 쉽게 티어링되 지 않고 표면에 밀착되면서(Fig. 14 참조) 지속시간이 길게 유지 하기 때문이다. 그 다음은 $\mathrm{PO}$ 계 $\mathrm{SGO}-167 \mathrm{~L}$ 이 좋은 조건으로 분석 되었다. 그러나 이 필름은 티어링이 초기에 생기고 밀려서 지속 시간이 짧은 경향이 SEM관찰에서 확인되었다(Fig. 13 참조).

\section{2 플라즈마 코팅재의 트라이볼러지 시험}

Fig. 7(a)는 포밍금형에 매우 유효할 것으로 예상되는 Concept 코팅 $\left(\mathrm{CrWN} / \mathrm{TiCN} / \mathrm{TiCN}_{2}\right.$ 다층 코팅)과 $\mathrm{CrN}$ 의 플라즈마 코팅 을 미처리재에 처리한 것의 마찰계수의 변화를 $50 \mathrm{~N}$ 과 $100 \mathrm{~N}$ 에 따라 시간으로 정리한 것이다.

또 Fig. 7(b)와 Fig. 7(c)는 UNSM 처리재에 Concept 코팅을 처 리한 시험편의 $50 \mathrm{~N}$ 과 $100 \mathrm{~N}$ 에 따라 시험한 결과를 각각 정리하 였다. 이때 구분하기 위하여 UNSM 처리재에 플라즈마 코팅을
실시한 것은 P-UNSM로 표시하였다.

이 Fig. 7(a)에서 concept $100 \mathrm{~N}$ 의 경우가 마찰계수가 제일 낮 았고, concept $50 \mathrm{~N}$ 은 높다가 0.83 에 근접하였다. 그리고 Fig. 7(c) 에서 P-UNSM30-100N의 경우가 Concept $100 \mathrm{~N}$ 과 거의 같은 곡 선을 나타내면서 마찰계수가 약 0.6 으로 제일 낮았다. Concept 코팅재는 $5.32 \mu \mathrm{m}, \mathrm{CrN}$ 코팅재는 $3.41 \mu \mathrm{m}$ 정도의 두께이므로 초 기에는 플라즈마 코팅의 영향으로 마찰계수가 낮아졌다가 약 250 300초부터 증가하기 시작하여 약 350초 이후에는 SM45C 모재의 마찰계수에 접근하려는 경향을 나타내었다.

Fig. 8은 Fig. 7의 트라이볼러지 시험중에 형성된 마모흔적의 폭과 깊이를 표면거칠기와 형상 측정기를 각각 이용하여 시험 편의 마모흔적의 중심부(Stroke $7.5 \mathrm{~mm}$ 인 곳)를 종류별로 측정 하여 정리한 것이다. 또 마모흔적의 폭과 깊이를 각각 Fig. 8(a) 와 Fig. 8(b)에 막대그림표로 비교하여 나타내었다.

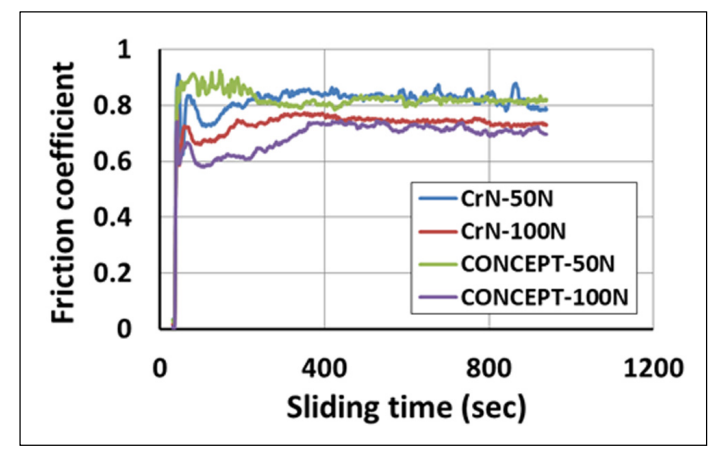

(a)

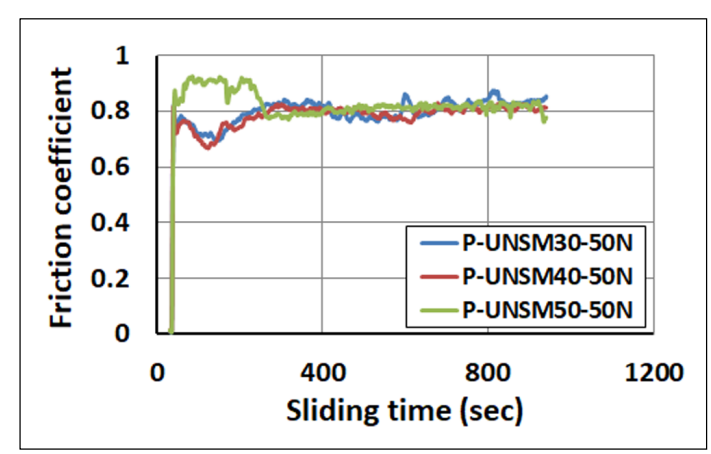

(b)

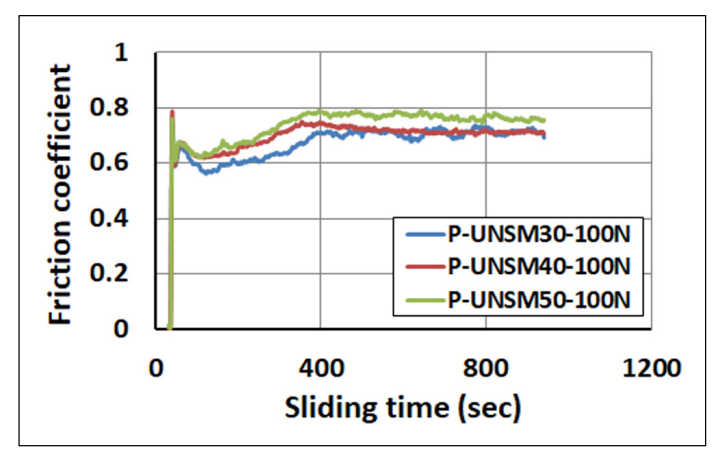

(c)

Fig. 7 Variation in friction coefficient of UNSM treated and plasma coated specimen at a normal load of $50 \mathrm{~N}$ and $100 \mathrm{~N}$ 


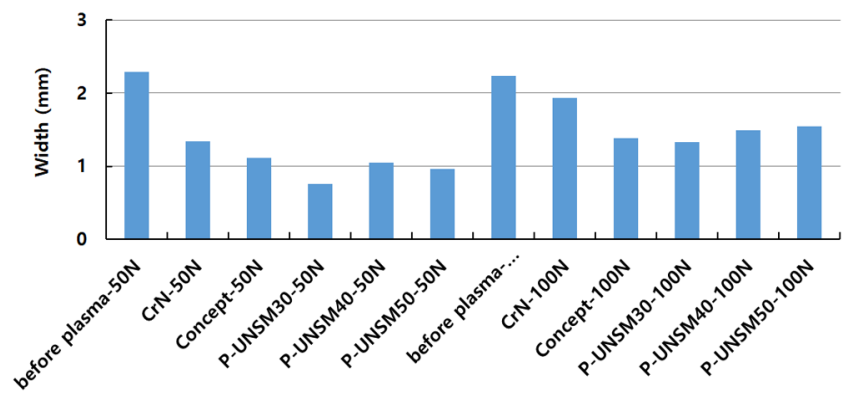

(a)

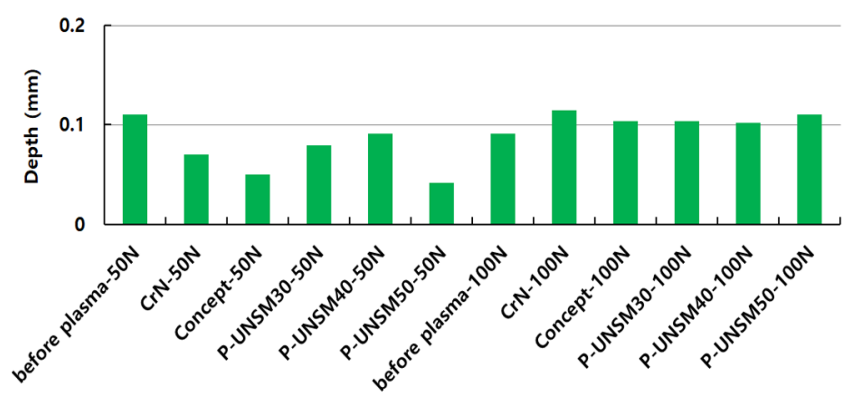

(b)

Fig. 8 Comparison of wear width (a) and depth (b) of the $\mathrm{CrN}$, concept coated specimens, and UNSM treated specimens

Table 6 Comparison of weight loss of the $\mathrm{CrN}$, concept coated specimens, and UNSM treated specimens

\begin{tabular}{ccccc}
\hline \hline \multirow{2}{*}{ Specimen } & \multicolumn{4}{c}{ Weight loss [g] } \\
& \multicolumn{2}{c}{$50 \mathrm{~N}$} & \multicolumn{2}{c}{$100 \mathrm{~N}$} \\
\hline Before plasma & 0.0171 & Base & 0.0142 & Base \\
CrN & 0.0162 & $-5.3 \%$ & 0.0151 & $+6.3 \%$ \\
Concept & 0.0048 & $-71.9 \%$ & 0.0106 & $-25.4 \%$ \\
P-UNSM30 & 0.0056 & $-67.3 \%$ & 0.0107 & $-24.6 \%$ \\
P-UNSM40 & 0.0076 & $-55.6 \%$ & 0.0112 & $-21.1 \%$ \\
P-UNSM50 & 0.0042 & $-75.4 \%$ & 0.0117 & $-17.6 \%$ \\
\hline
\end{tabular}

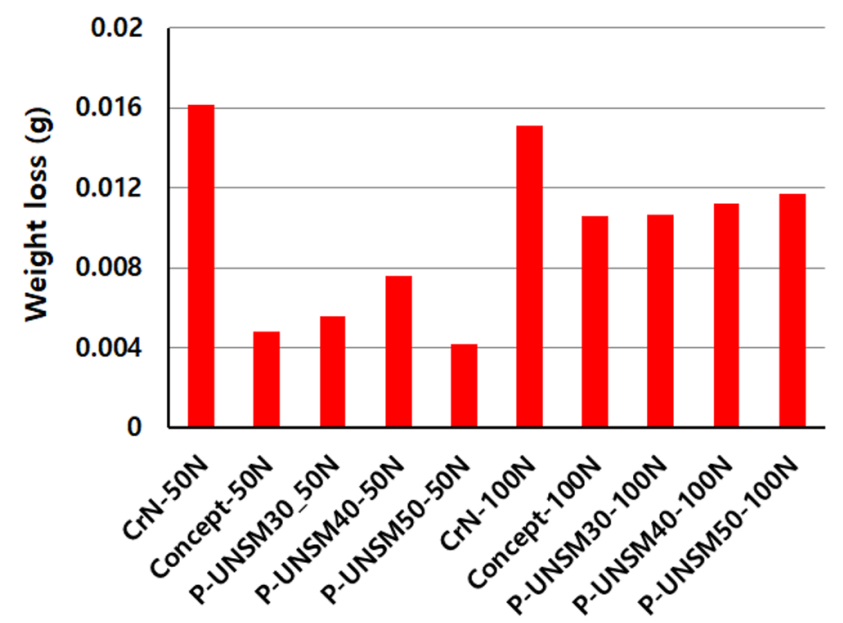

Fig. 9 Variation in weight loss of the $\mathrm{CrN}$, concept coated specimens, and UNSM treated specimens
여기서 미처리재에 비교하여 Concept $50 \mathrm{~N}$ 은 약 $53 \%, \mathrm{CrN}$ $50 \mathrm{~N}$ 은 약 $35 \%$ 정도 폭과 깊이의 감소량이 적었다.

또 P-UNSM재는 미처리재에 비교하여 폭이 약 $60 \%$ 정도 적 게 감소하였다. 이렇게 P-UNSM재가 Concept재와 CrN재 보다 마모흔적의 폭이 적은 것은 UNSM 처리에 의한 표면경도 상승, 조직의 나노화와 압축잔류응력의 형성에 세라믹 플라즈마 코팅 의 영향이 첨가됨으로 생긴 것으로 평가된다(Amanov et al., 2014; Amanov et al., 2012; Suh et al., 2007).

Table 6과 Fig. 9은 하중 $50 \mathrm{~N}$ 과 $100 \mathrm{~N}$ 에서 시험편 종류별로 트라 이볼러지 시험 전 후의 무게감소량을 비교한 것이다. 이 자료에서 플라즈마 코팅재는 미처리재에 비교하여 무게 감소량이 매우 적음 을 알 수 있다. 특히 $50 \mathrm{~N}$ 인 경우, Concept 코팅재와 P-UNSM 처리재 는 마모량이 약 55 75\% 감소하는 경향을 나타내었다.

또 Concept 코팅재가 $\mathrm{CrN}-50 \mathrm{~N}$ 쪽과 $\mathrm{CrN}-100 \mathrm{~N}$ 쪽 보다 마모량이 $66.6 \%$ 와 $31.7 \%$ 감소하는 경향을 나타내었는데, 이것은 concept 코팅은 $\mathrm{CrWN} / \mathrm{TiCN} / \mathrm{TiCN}_{2}$ 의 다층코팅으로 $\mathrm{Ti}$ 와 $\mathrm{W}$ 의 화합물 이 강하게 형성되며, 코팅층의 두께가 $\mathrm{CrN}$ 쪽 보다 두껍기 때문에 마멸이 적게 생기는 것 같다. 이러한 현상은 Concept 코팅이 $\mathrm{CrN}$ 보다 마모 폭과 깊이가 적게 감소한 Fig. 8의 결과와도 잘 일치하 는 경향이다. 또한 $\mathrm{CrN}$ 은 Concept 코팅보다 마멸현상이 약간 크 므로 모재의 마모량이 증가되는 것도 예상된다.

\section{3. 트라이볼러지 시험후의 SEM 관찰}

\subsubsection{Concept 코팅재의 SEM관찰}

Fig. 10은 트라이볼러지 시험한 시편의 SEM 관찰 결과를 예 시한 것이다. Fig. 10 (a)는 Concept 코팅재에 하중 $50 \mathrm{~N}$ 에서 1,800 초 후의 마모상태로 마멸트랙을 2개의 화살표로 나타내었다. 마 멸트랙 내에는 마멸흔적이 보이며 주로 융착 미끄럼(Adhesive

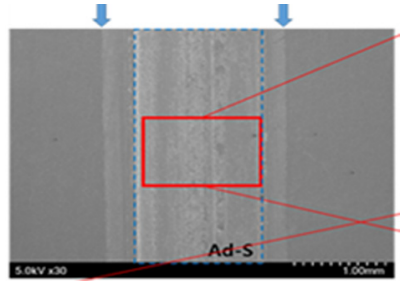

(a)

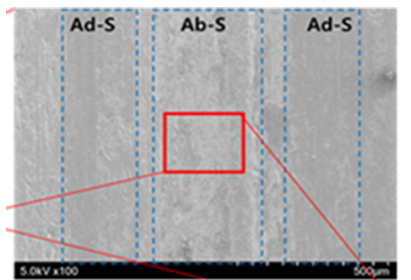

(b)

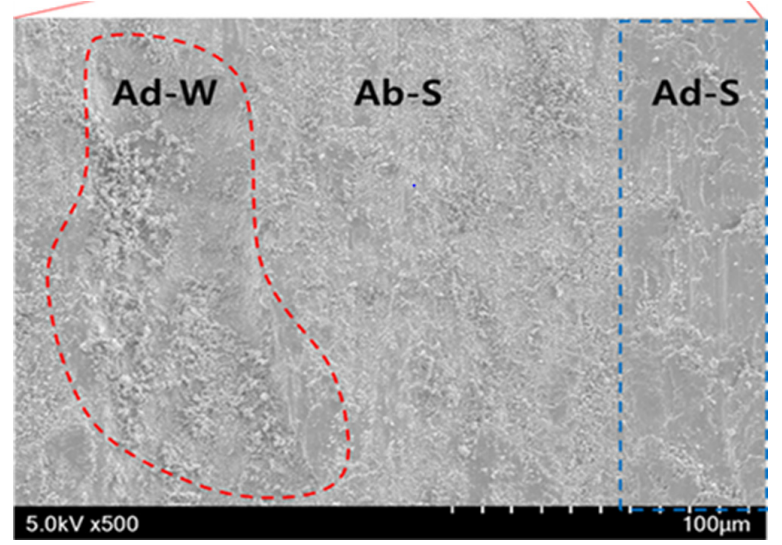

(c)

Fig. 10 SEM images ((a) $30 \times$, (b) $100 \times$ and (c) $500 \times$ ) at the center of concept coated specimen at load $50 \mathrm{~N}$ and after $1800 \mathrm{sec}$. 


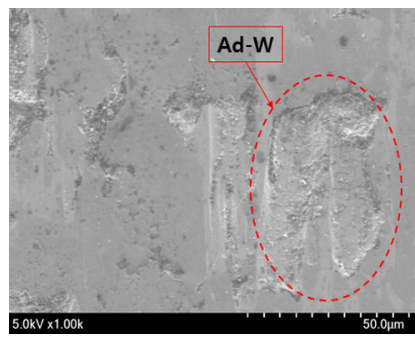

(a)

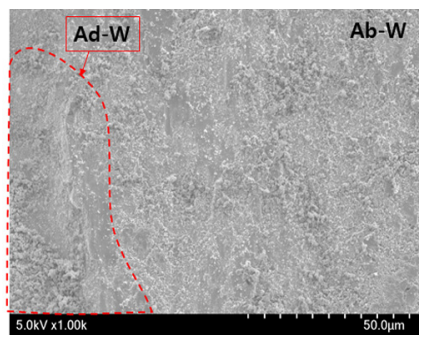

(b)
Fig. 11 Comparison of SEM images $1000 \times$ at the center of uncoated SM45C specimen (a), concept coated SM45C specimen (b)

sliding, Ad-S)으로 보여 진다. 마모된 중앙부를 Fig. 10(b)와 같 이 100 배로 확대하면 $\mathrm{Ad}-\mathrm{S}$ 이 좌우에 잘 나타나며 마멸이 가장 심한 중앙은 코팅층이 입자형태로 잔존하였고 융착에 의한 마 멸(Adhesive wear, Ad-W)도 관찰되었다.

Fig. 10(c)는 Fig. $10(\mathrm{~b})$ 의 사각형 부분을 500배로 확대한 것이 며, 융착에 의한 큰 마멸부가 좌측에 $\mathrm{Ad}-\mathrm{W}$ 로 관찰되고 우측은 $\mathrm{Ad}-\mathrm{S}$ 이 관찰되었으며, 전체 면에는 입자들에 의한 연삭미끄럼 (Abrasive sliding, $\mathrm{Ab}-\mathrm{S}$ )이 주로 관찰되었다.

Fig. 11(a)는 코팅을 하지 않은 SM45C 모재의 마멸의 특징을 나타낸 것으로 표면과 크게 구분이 되는 점이 관찰되었다. 전체 적인 표면은 연삭마멸(Abrasive wear, $\mathrm{Ab}-\mathrm{W}$ )이 크게 작용하고 있고, 융착에 의해 큰 탈락이 발생한 $\mathrm{Ad}-\mathrm{W}$ 의 경계면은 코팅을 하지 않았을 때는 명확하게 나타났으나 코팅한 시험편 쪽인 Fig. 11(b)에는 미약하다.

그 원인은 코팅층 Debris의 영향으로 연삭을 일으키며 이러한 입자들은 미끄럼 운동 중에 Three-body abrasion을 일으키기 때 문이다. 이 마멸은 모재보다 경도가 높은 물질이 존재 할 때 잘 나타나는 현상으로, 본 연구에서는 $\mathrm{Ti}$ 를 포함하는 코팅층이 입 자들로 잔존하면서 모재와 상대재 사이에서 연삭마멸을 일으키 는 것을 의미한다.

즉, Concept와 같은 $\mathrm{PVD}$ 코팅을 한 경우 코팅입자들의 영향 으로 국부적으로 $\mathrm{Ad}-\mathrm{S}$ 와 $\mathrm{Ab}-\mathrm{S}$ 이 복합적으로 발생하게 되며 마 멸 또한, $\mathrm{Ad}-\mathrm{W}$ 와 $\mathrm{Ab}-\mathrm{W}$ 가 복합적으로 발생하였다.

\subsection{2. $\mathrm{PO} / \mathrm{PVC}$ 계 필름재의 표면관찰}

Fig. 12(a)는 PO계 필름인 SGO-167L를 부착하여 트라이볼러 지 시험된 상태를 예시하였고, 이 자료에서 필름이 티어링 된 것을 육안으로 관찰 가능하다. Fig. 12(b)는 PVC계 필름인 $\mathrm{SGV}-227$ 의 트라이볼러지 시험된 상태를 나타내었고, 이 필름은 티어링 되면서 표면 이탈하는 현상을 육안으로 관찰 가능하다. Fig. 12(c)는 PVC계 필름인 SGV-280F의 트라이볼러지 시험된 상태를 나타내었다. 그러나 SGV-280F 시험편은 티어링이 잘 생 기지 않고 밀착된 특징을 나타내었고, 이러한 미시적인 표면 관 찰은 Fig. 14의 7장의 연결 SEM관찰에서 확인할 수 있다. Fig. 12(d)는 Fig. 12(c)의 시험편에 SEM 촬영 전 필름에 백금코팅을 실시한 경우를 예시하고 있다.

Fig. 13은 Fig. 12(a)의 필름이 마멸된 SGO-167L시험편의 7장 의 연결 $\mathrm{SEM}$ 사진이고, 중앙부의 타원으로 표시한 부분이 마모 에 의한 모재가 노출되었다. Fig. 14는 SGV-280F의 연결 SEM사

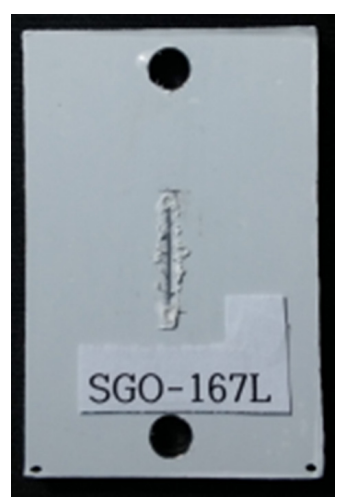

(a)

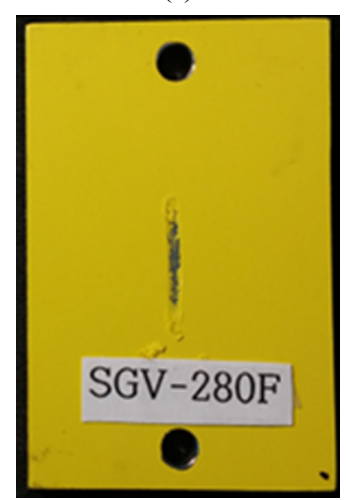

(c)

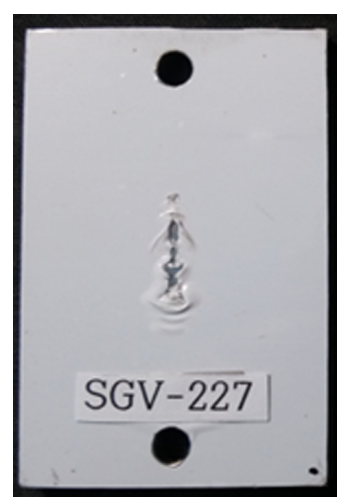

(b)

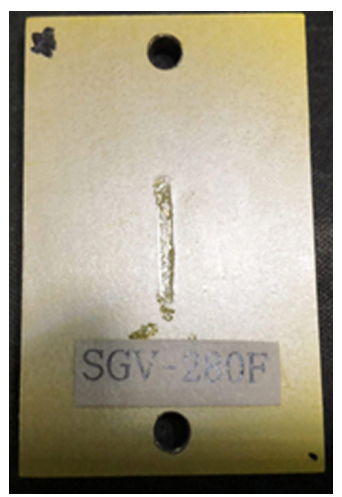

(d)
Fig. 12 Appearance of test specimen with films: (a) SGO-167L, (b) SGV-227, (c) SGV-280F, (d) Platinum coating on film before SEM shooting

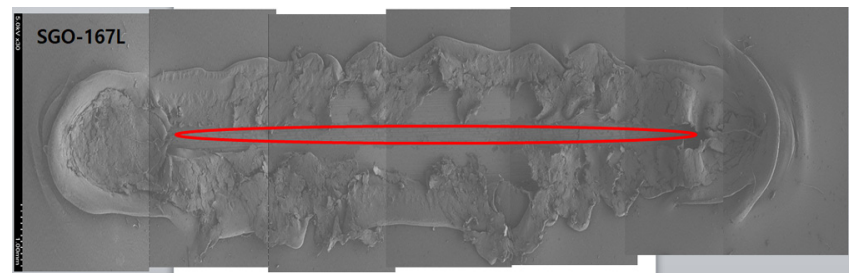

Fig. 137 connection SEM photographs of SGO-167L specimen with the film tearing

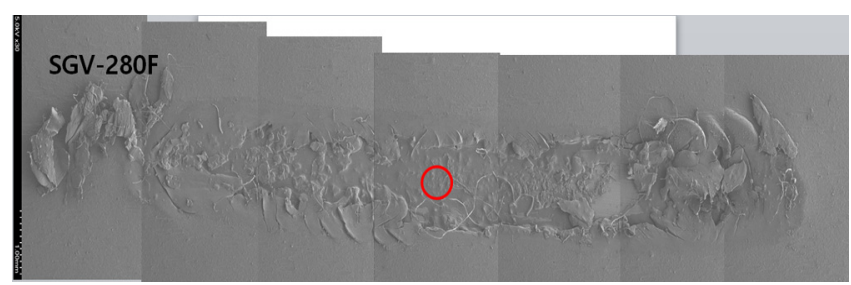

Fig. 147 connection SEM photographs of SGV-280F specimen with keeping in close contact and maintaining longer time

진이며, 일부의 필름이 떨어져서 전후로 약간 밀렸지만, 30 배의 저배율에서 마모에 의한 모재가 노출되지 않았다. 따라서 3 가지 필름중에 SGV-280F의 마멸특성이 가장 우수하였고, 또한 마찰 계수가 본 연구에서 가장 낮았다.

Fig. 15는 Fig. 13 의 SGO-167L 중앙부의 500 배와 3000 배의 확 

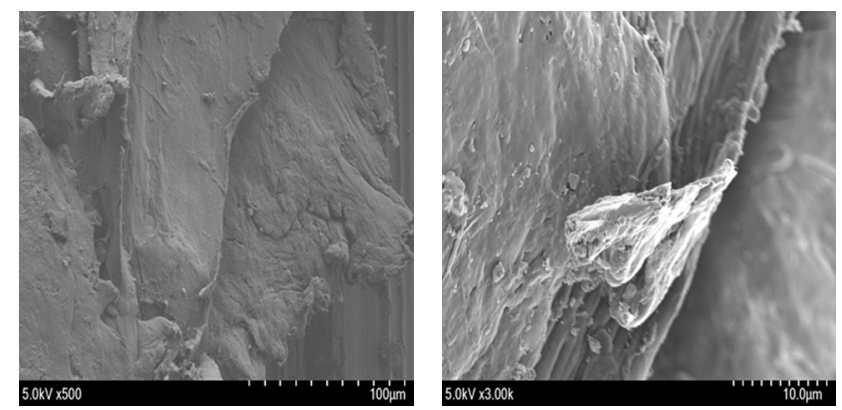

Fig. 15 Magnified SEM images of the central part of Fig. 13, showing the film was teared and pushed, and the base material was exposed

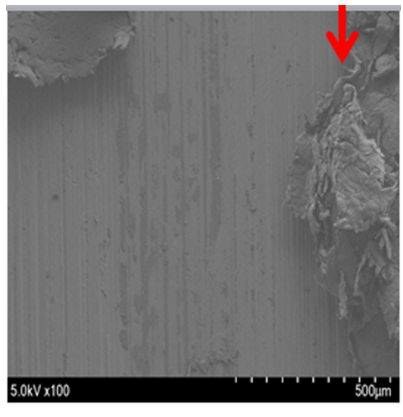

(a) $100 \times$

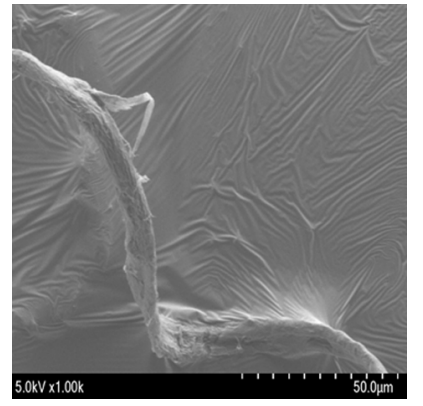

(b) $1000 \times$
Fig. 16 SEM photographs enlarged the state of film adhesion of SGV-280F to $100 \times$ and $1000 \times$

대 $\mathrm{SEM}$ 사진이며, 이 사진에서 필름이 떨어져서 밀렸고, 모재가 노출됨을 관찰할 수 있다.

Fig. 16은 Fig. 14의 중앙부에 원으로 표시된 부분의 확대 사 진으로 Fig. 16(a)에서 화살표로 표시한 곳이 볼과 필름과의 경 계부에서 필름이 밀린 상태를 100 배로 확대하였고, Fig. 16(b)는 1,000 배로 필름이 밀림 상태를 확대하였다. 이와 같이 SGV$280 \mathrm{~F}$ 시험편은 $\mathrm{SGO}-167 \mathrm{~L}$ 과 SGV-227 시험편 보다 필름이 쉽게 티어링되지 않고 표면에 밀착되면서 지속시간이 길게 유지하기 때문에 마찰계수가 가장 적었으며, 트라이볼러지 특성이 좋아 짐을 나타내었다.

\subsection{3. 플라즈마 코팅재의 $\mathrm{SEM}$ 관찰과 $\mathrm{EDS}$ 분석}

Fig. 17는 SM45C재에 Concept 코팅(a) 된 것과 $\mathrm{CrN}$ 코팅(b) 된 것의 마모흔적의 끝부분(tip)을 50 배와 1,000 배로 확대한 사 진을 나타내었고, 이 1,000 배로 확대한 끝부분과 중앙부의 SEM 영상에서 $\mathrm{EDS}$ (Energy dispersive spectroscopy) 분석법으로 주요 성분을 분석한 결과를 표로 정리하였다. 여기에서 마모흔적의 Tip인 양끝부분에서는 다량으로 Concept 코팅 성분과 $\mathrm{CrN}$ 이 마 모되어 축적 될 것으로 예상했지만, 마모흔적의 끝부분과 중앙 부의 성분은 매우 유사하였다.

즉 플라즈마 코팅은 밀착성이 높아서 어떤 성분이 밀려서 축 적되지 않음을 알 수 있었다. 그리고 $\mathrm{EDS}$ 분석에서 $\mathrm{W}, \mathrm{Cr}, \mathrm{Si}$ 는 미량이고 다른 계열의 성분과 Overlap현상이 생기므로 검출이 어려웠다. 따라서 Fig. 17와 표에는 $\mathrm{W}$ 량은 검출되지 않았고, Concept 코팅재 중앙부분에서 $\mathrm{Ti}$ 가 $0.71 \%$ 검출되었다.
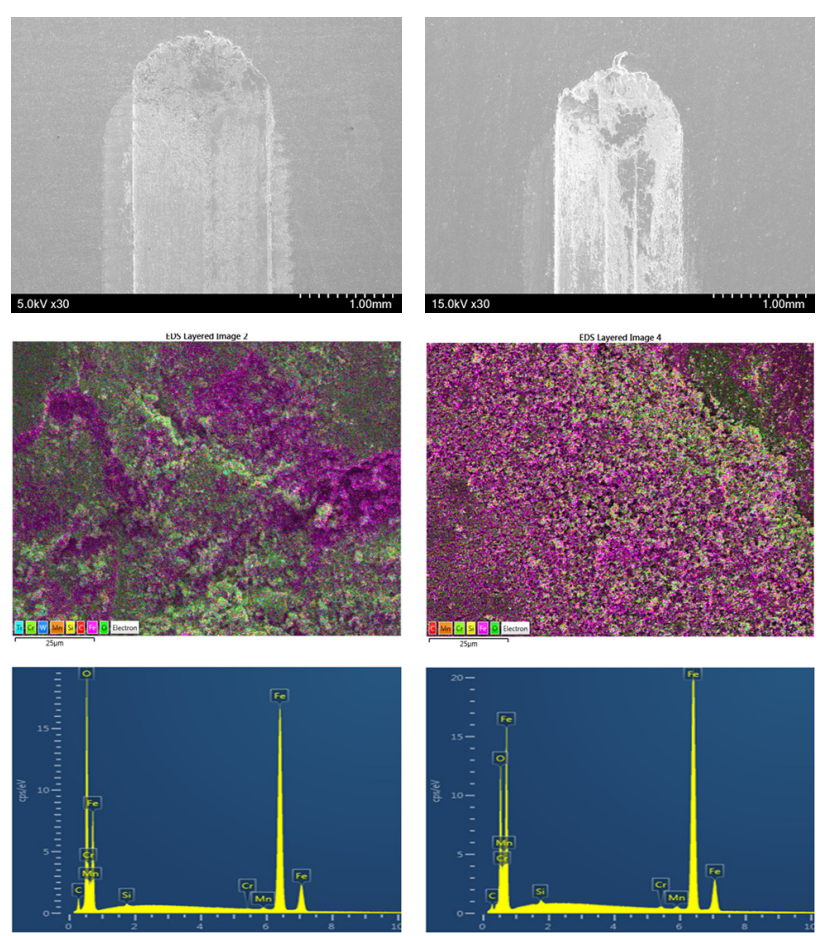

\begin{tabular}{|c|c|c|}
\hline & $\begin{array}{c}\text { Tip } \\
\text { Wt \% }\end{array}$ & $\begin{array}{c}\text { Center } \\
\text { Wt \% }\end{array}$ \\
\hline $\mathrm{C}$ & 2.31 & 1.94 \\
\hline $\mathrm{O}$ & 13.93 & 14.41 \\
\hline $\mathrm{Si}$ & 0.11 & 0.17 \\
\hline $\mathrm{Cr}$ & 0.08 & - \\
\hline $\mathrm{Ti}$ & - & 0.71 \\
\hline $\mathrm{Mn}$ & 0.60 & 0.59 \\
\hline $\mathrm{Fe}$ & 82.96 & 82.18 \\
\hline
\end{tabular}

(a) The tip of concept-100 N specimen

\begin{tabular}{|c|c|c|}
\hline & $\begin{array}{c}\text { Tip } \\
\text { Wt \% }\end{array}$ & $\begin{array}{c}\text { Center } \\
\text { Wt \% }\end{array}$ \\
\hline $\mathrm{C}$ & 0.72 & 1.05 \\
\hline $\mathrm{O}$ & 7.59 & 4.88 \\
\hline $\mathrm{Si}$ & 0.16 & 0.18 \\
\hline $\mathrm{Cr}$ & 0.37 & 0.35 \\
\hline $\mathrm{Mn}$ & 0.69 & 0.71 \\
\hline $\mathrm{Fe}$ & 90.46 & 92.84 \\
\hline
\end{tabular}

(b) The tip of $\mathrm{CrN}-100 \mathrm{~N}$ specimen
Fig. 17 SEM and EDS analysis of SM45C material expanded on concept coating-100 N (a), CrN coating-100 N (b)

Fig. 18은 트라이볼러지 시험한 P-UNSM-40N-100N재의 마멸 끝부분을 50 배(Fig. 18(a))로 확대하면서 EDS 분석법으로 영상 전체의 성분을 분석한 예를 나타내었다.

또 이러한 $\mathrm{EDS}$ 성분의 무게비율(\%)의 분석결과를 Fig. 18(b) 와 (d)에 나타내었고, Fig. $18(\mathrm{c})$ 는 C, N, Ti, $\mathrm{Cr}, \mathrm{Mn}$ 과 $\mathrm{Fe}$ 의 각 성분원소의 분포상태를 도시하였다.

이 $\mathrm{EDS}$ 분석에서 $\mathrm{Ti}$ 가 관찰된 표면전체에서 제일 높게 $39.59 \%$ 검출되었고, $\mathrm{W}$ 을 위시한 일부성분은 미량이고 다른 계 열의 성분과 Overlap 현상에 생기므로 검출이 어려웠다.

Fig. 19는 트라이볼러지 시험한 $\mathrm{CrN}-100 \mathrm{~N}$ 시험편의 마멸 끝 부분을 저배율인 50배(Fig. 19(a))로 확대하면서 EDS 분석으로 관찰영역의 성분을 분석한 예이다. 각 성분원소의 $\mathrm{EDS}$ 성분의 영역을 나타내었고, 무게비율(\%) 분석결과로 정리한 것이 Fig. 19(b)-(d)이다. Fig. 19(c)에서 시험편의 주성분인 C, N, Cr, Mn, $\mathrm{Fe}$ 와 $\mathrm{W}$ 의 분포상태를 나타내었고, 이 경우에는 $\mathrm{Cr}$ 가 가장 높게 $26.21 \%$ 검출되었다. 


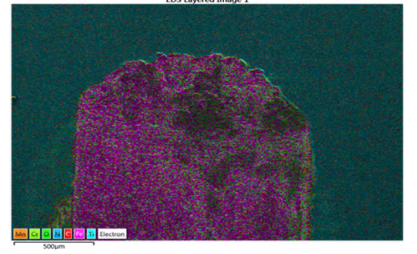

(a)
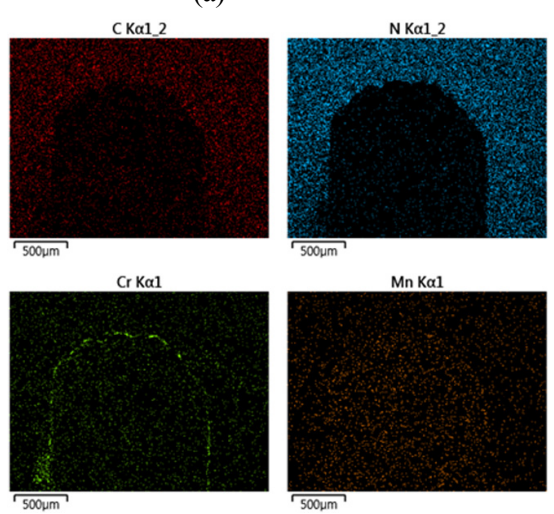

(c)

\begin{tabular}{|c|c|}
\hline & Wt \% \\
\hline $\mathrm{C}$ & 6.11 \\
\hline $\mathrm{N}$ & 4.21 \\
\hline $\mathrm{O}$ & 11.25 \\
\hline $\mathrm{Si}$ & 0.10 \\
\hline $\mathrm{Ti}$ & 39.59 \\
\hline $\mathrm{Cr}$ & 0.83 \\
\hline $\mathrm{Mn}$ & 0.28 \\
\hline $\mathrm{Fe}$ & 37.64 \\
\hline
\end{tabular}

(d)

Fig. 18 EDS analysis on the tip of concept coated P-UNSM40N$100 \mathrm{~N}$ specimen.

\section{4. 결 론}

$\mathrm{SM} 45 \mathrm{C}$ 재에 표면처리기술로 마이크로 포징(Micro forging)기 술인 초음파나노표면개질(UNSM) 기술을 표면증착방식으로 플 라즈마 코팅인 Concept 다층코팅과 $\mathrm{CrN}$ 코팅과 융합 적용하면서 트라이볼러지 시험을 실시하여 프레스 금형용 마찰특성의 자료 를 축적하기 위한 일련의 연구에서 다음과 같은 결과를 얻었다.

Concept 코팅 $100 \mathrm{~N}$ 의 마찰계수가 약 0.6 으로 낮았고, P-UNSM$30-100 \mathrm{~N}$ 의 경우가 Concept $100 \mathrm{~N}$ 과 거의 같은 곡선을 나타내면서 마찰계수가 약 0.6 으로 낮았다. Concept 코팅은 $5.32 \mu \mathrm{m}$ 의 두께로 초기에는 플라즈마 코팅의 영향으로 마찰계수가 낮아졌다가 약 250 300초부터 증가하기 시작하여 약 350초 이후에는 SM45C 모 재의 마찰계수에 접근하려는 경향을 나타내었다.

$\mathrm{CrN}$ 과 Concept 코팅재의 시험편에 트라이볼러지 시험 전과 후의 무게 변화량을 미처리재에 대하여 비교하면, $50 \mathrm{~N}$ 인 경우, Concept 코팅재와 UNSM 처리재에 Concept 코팅을 처리한 P-UNSM 처리재 는 마모량이 약 55 75\% 감소하는 경향을 나타내었다.

또 Concept 코팅재가 CrN-50N쪽과 $\mathrm{CrN}-100 \mathrm{~N}$ 쪽 보다 마모량이 $66.6 \%$ 와 $31.7 \%$ 감소하는 경향을 나타내었는데, 이것은 Concept

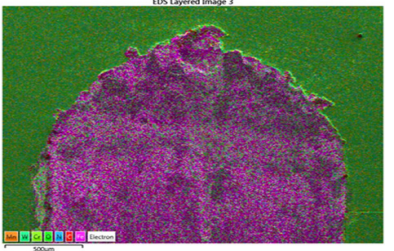

(a)
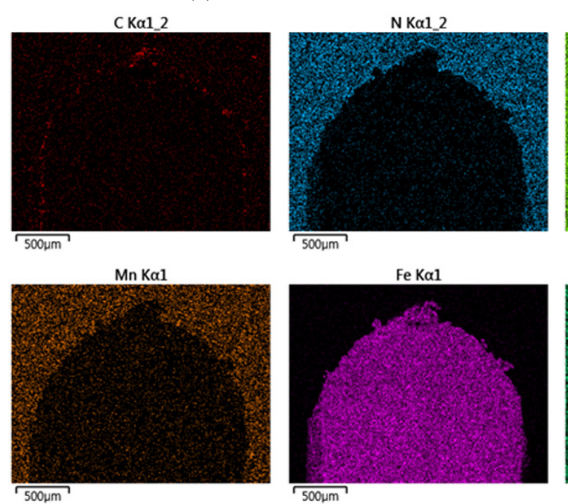

(c)

(d)

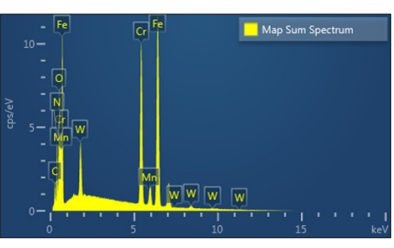

(b)
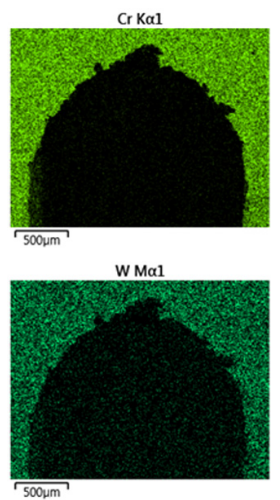

$500 \mathrm{um}$

\begin{tabular}{|c|c|}
\hline & Wt \% \\
\hline $\mathrm{C}$ & 2.99 \\
\hline $\mathrm{N}$ & 6.31 \\
\hline $\mathrm{O}$ & 4.42 \\
\hline $\mathrm{W}$ & 5.29 \\
\hline $\mathrm{Cr}$ & 26.21 \\
\hline $\mathrm{Mn}$ & 0.35 \\
\hline $\mathrm{Fe}$ & 54.43 \\
\hline
\end{tabular}

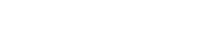

Fig. 19 EDS analysis on the tip of CrN coating-100N specimen.

코팅은 $\mathrm{CrWN} / \mathrm{TiCN} / \mathrm{TiCN} 2$ 의 다층코팅으로 $\mathrm{Ti}$ 와 $\mathrm{W}$ 의 화합물 이 강하게 형성되었으며, 코팅층의 두께가 $\mathrm{CrN}$ 쪽 보다 두껍기 때 문에 마멸이 늦게 생기는 것 같다.

SGV-280F 필름 부착시험편은 일부의 필름이 밀렸지만, 마모에 의한 모재인 SM45C가 노출되지 않았다. 또 이 필름은 SGO-167L 과 SGV-227 시험편 보다 티어링 되지 않고 표면에 밀착되면서 지속시간이 길게 유지되었기에 마찰계수가 평균 0.22 로 본 연구 에서 가장 적었다.

$$
\text { 후 기 }
$$

본 연구는 KEIT(Korea Evaluation Institute of Industrial Technology) 의 조선해양산업핵심기술개발사업(과제번호 : 10077592)의 지원으 로 수행되었습니다.

\section{References}

Amanov, A., Cho, I.S., Pyoun, Y.S., Lee, C.S., Park, I.G., 2012. Micro-dimpled Surface by Ultrasonic Nanocrystal Surface 
Modification and Its Tribological Effects. Wear, 286, 136-144. Amanov, A., Cho, I.S., Sasaki, S., 2014. The Influence of DLC Coating on the Mechanical and Frictional Properties of Unpeened and Peened Cu-based Bimetal under Dry Sliding Conditions. Materials Chemistry and Physics, 143, 814-824.

Chun, M.S., Kim, M.H., Kim, W.S., Kim, S.H., Lee, J.M., 2009. Experimental Investigation on the Impact Behavior of Membrane Type LNG Carrier Insulation System. Journal of Loss Prevention in the Process Industries, 22(6), 901-907.

Gim, J.S., Jeong, Y.T., 2007. Introduction to PVD/PACVD Coating. Journal of the Korean Society for Precision Engineering, 24(5), 7-13.

Jeon, Y.J., Kim, S.H., Yoon, K.T., Heo, Y.M., Lee, T.G., 2014. Indirect Prediction of Surface Damage for a Press Die with Wear Characteristics and Finite Element Stamping Analysis. Transactions of Materials Processing, 23(1), 29-34.

Kim, B.C., Yoon, S.H., Lee, D.G., 2011. Pressure Resistance of the Corrugated Stainless Steel Membranes of LNG Carriers. Ocean Engineering, 38, 592-608.

Kim, H.S., Chun, M.S., Lee, J.M., Kim, M.H., 2013. A Comparative Evaluation of Fatigue and Fracture Characteristics of Structural Components of Liquefied Natural Gas Carrier Insulation System. Journal of Pressure Vessel Technology, 135(2), 021405.
Kim, M.H., Lee, S.M., Lee, J.M., Noh, B.J., Kim, W.S., 2010. Fatigue Strength Assessment of MARK-III Type LNG Cargo Containment System. Ocean Engineering, 37, 1243-1252.

Lee, S.C., Kim, J.H., Kim, H.D., Choi, G.S., Amanov, A., and Pyun, Y.S., 2015. Changes in Mechanical Properties of WC-Co by Ultrasonic Nanocrystal Surface Modification Technique. Journal of The Korean Society of Tribologists and Lubrication Engineers, 31(4), 157-162.

Pyun, Y.S., Suh, C.M., Yamaguchi, T., Im, J.S., Kim, J.H., Amanov, A., Park, J.H., 2012. Fatigue Characteristics of SAE52100 Steel via Ultrasonic Nanocrystal Surface Modification Technology. Journal of Nanoscience and Nanotechnology, 12, 6089-6095.

Suh, C.M., Nahm, S.H., Kim, J.H., Pyun, Y.S., 2016. A Study on the VHCF Fatigue Behaviors of Hydrogen Attacked Inconel 718 Alloy. Transactions of the Korean Society of Mechanical Engineers A, 40(7), 637-646.

Suh, C.M., Song, G.H., Suh, M.S., Pyoun, Y.S., 2007. Fatigue and Mechanical Characteristics of Nanostructured Tool Steel by Ultrasonic Cold Forging Technology. Materials Science and Engineering: A, 443(1-2), 101-106.

Yu, Y.H., Kim, B.G., Lee, D.G., 2013. Cryogenic Reliability of the Sandwich Insulation Board for LNG Ship. Composite Structures, 95, 547-556. 